\title{
Carbon and Energy Storage in Bacteria
}

\author{
By J. F. WILKINSON \\ Bacteriology Department, University of Edinburgh, Edinburgh
}

Many compounds have been assumed to act as storage materials in bacteria. Those most commonly implicated as specialized carbon and energy reserves are intracellular polysaccharides particularly polyglucoses such as glycogen and starch, and lipids, particularly poly- $\beta$-hydroxybutyrate (reviewed by Wilkinson, 1959). The evidence available suggests that polyglucoses and lipids act as alternative reserves depending upon the bacterial species and upon the nature of the carbon and energy source in the environment. Thus all the enterobacteria can store glycogen while most Bacillus species can store poly- $\beta$-hydroxybutyrate. On the other hand, Stanier, Doudoroff, Kunisawa \& Contopoulou (1959) have shown that the product of photosynthetic assimilation in Rhodospirillum rubrum depends on the substrate used. Acetate and butyrate were converted to poly- $\beta$-hydroxybutyrate while malate or succinate formed a polyglucose. It is probable that the ability to form such alternative reserves is common among bacteria. Dagley \& Johnson (1953) studied lipid and polysaccharide production in Escherichia coli and showed that while acetate stimulated lipid production and depressed polysaccharide production, glucose had the opposite effect. Similarly, Bacillus megaterium synthesizes an appreciable amount of glycogen as well as poly- $\beta$-hydroxybutyrate (Barry, Gavard, Milhaud \& Aubert, 1953). It can be expected that a carbon and energy reserve will be synthesized or broken down depending upon whether there is an excess or a deficiency of the carbon and energy sources available. As examples, glycogen synthesis in $E$. coli and poly- $\beta$-hydroxybutyrate synthesis in $\boldsymbol{B}$. megaterium will be considered.

\section{Synthesis of glycogen and poly- $\beta$-hydroxybutyrate}

Both glycogen and poly- $\beta$-hydroxybutyrate can accumulate in large amounts within the cell, particularly in the stationary phase when growth is limited by a deficiency of some factor other than the carbon and energy source. Thus, in a nitrogen-deficient medium, Escherichia coli can synthesize as much as $20 \%$ of its dry weight as glycogen (Holme \& Palmstierna, 1956b) and Bacillus megaterium as much as $40 \%$ of its dry weight as poly- $\beta$-hydroxybutyrate (Macrae \& Wilkinson, $1958 a$ ). This accumulation is the result of an unbalanced growth in the stationary phase and is equivalent to conditions in a washed suspension provided with a suitable carbon and energy source. However, these large amounts are produced only under abnormal conditions analogous to what Foster (1947) has called a 'hothouse' environment. Do glycogen and poly- $\beta$-hydroxybutyrate occur in appreciable quantities in cells grown under conditions analogous to those occurring in nature? It is difficult to reproduce in the laboratory natural conditions for organisms like E. coli and B. megaterium. For example, the supply of the carbon and energy source will probably be intermittent. However, glycogen and poly- $\beta$-hydroxybutyrate 
can accumulate in the exponential phase of growth as evidenced by continuous culture experiments.

In most of the published work on polysaccharide production in continuous culture, it is impossible to distinguish between intracellular polyglucoses and extracellular structural polysaccharides. However, Holme (1957) has studied glycogen production in $E$. coli growing at various dilution rates (i.e. growth rates) in a

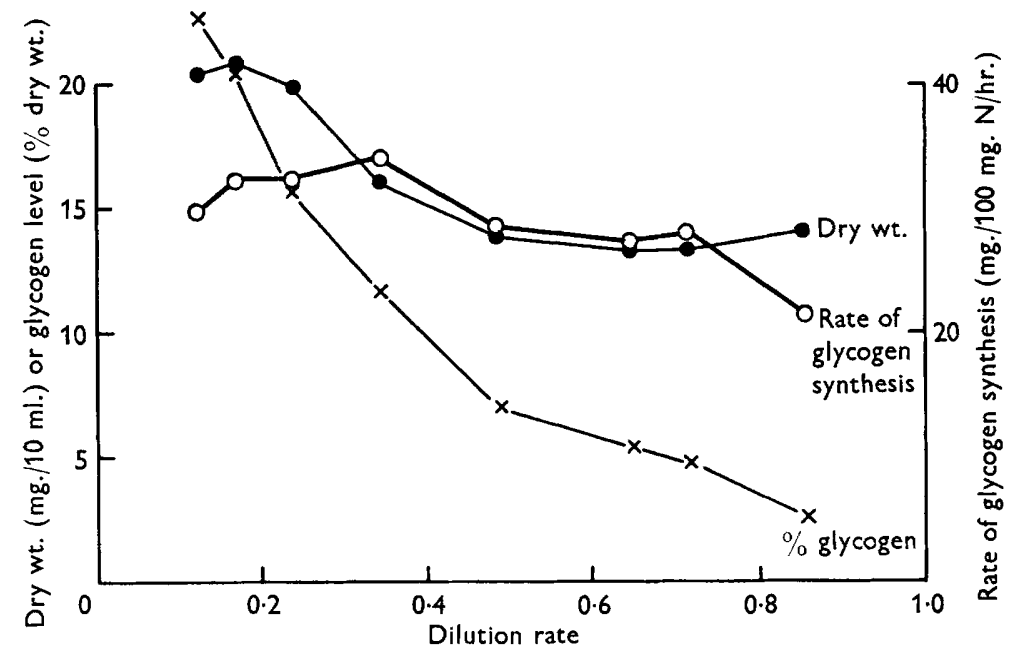

Fig. 1. The effect of the dilution rate (growth rate) in nitrogen-deficient continuous cultures of Escherichia coli upon the dry weight of the culture, the percentage of glycogen in the cells and the rate of glycogen synthesis., Dry weight; $\times, \%$ glycogen; 0 , rate of glycogen synthesis. From Holme, 1957.

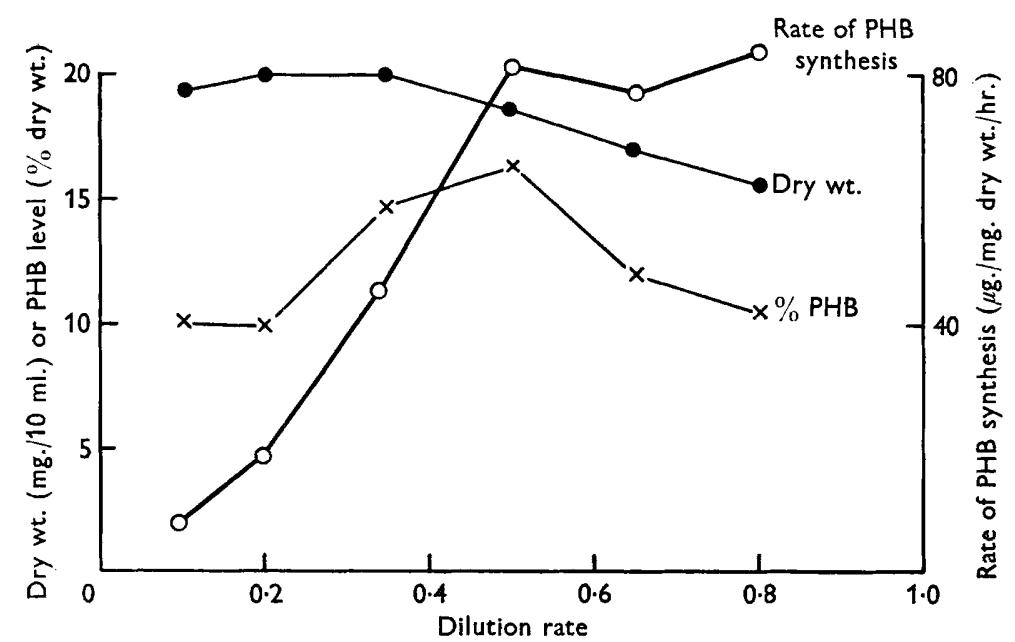

Fig. 2. The effect of the dilution rate (growth rate) in nitrogen-deficient continuous cultures of Bacillus megaterium upon the dry weight of the culture, the percentage of poly- $\beta$-hydroxybutyrate in the cells and the rate of poly- $\beta$-hydroxybutyrate synthesis. , Dry weight; $\times, \%$, poly- $\beta$-hydroxybutyrate; 0 , rate of poly- $\beta$-hydroxybutyrate synthesis. From Munro \& Wilkinson (unpublished results). 
nitrogen-deficient simple defined medium with glucose as the carbon and energy source. Some of his results are shown in Fig. 1. It is evident that the rate of glycogen production per unit amount of cell nitrogen was roughly constant at all growth rates. Glycogen production under balanced growth must occur at a similar rate to that under unbalanced growth, resulting in a higher content of glycogen at low dilution rates. We have studied poly- $\beta$-hydroxybutyrate production in nitrogendeficient cultures of $\boldsymbol{B}$. megaterium (Munro \& Wilkinson, unpublished data) Typical results are given in Fig. 2 and show that appreciable amounts of poly- $\beta$ hydroxybutyrate were produced at all growth rates although the rate of synthesis was higher at high dilution rates. In both $\boldsymbol{E}$. coli and $\boldsymbol{B}$. megaterium, the level of the storage product at high dilution rates corresponded to that in the exponential phase of growth in batch culture in a simple synthetic medium with glucose as the carbon and energy source. Presumably in such a medium, some factor other than the rate of utilization of the carbon and energy source is limiting the rate of growth. Under these circumstances, intermediates of the main pathway for the breakdown of the carbon and energy source are either excreted by the cell (e.g. pyruvic and oxoglutaric acids) or are converted to storage polymers. Unfortunately there are no figures available for glycogen synthesis in carbon and energy-deficient continuous culture of $\boldsymbol{E}$. coli although preliminary experiments in this laboratory with $\boldsymbol{B}$. megaterium suggest a very low level for both poly- $\beta$-hydroxybutyrate and glycogen at low dilution rates.

\section{Breakdown of glycogen and poly- $\beta$-hydroxybutyrate}

The subject of endogenous metabolism has been reviewed recently by Dawes \& Ribbons (1962). It is evident that many substances can act as substrates for endogenous metabolism depending upon the micro-organism and upon the conditions of growth, but it is certain that glycogen and poly- $\beta$-hydroxybutyrate can be broken down at a rapid rate by 'resting' cells and can act as primary endogenous substrates. Thus Ribbons \& Dawes (1963) have concluded that glycogen is the primary endogenous substrate for Escherichia coli and that only when it is exhausted will net degradation of other substrates such as ribonucleic acid and protein occur. The term 'net degradation' must be emphasized since Mandelstam (1960) has pointed out that turnover of ribonucleic acid and protein occurs as soon as balanced growth ceases. Poly- $\beta$-hydroxybutyrate can also be a major substrate for endogenous respiration in Bacillus megaterium (Macrae \& Wilkinson, 1958b), although its breakdown is rarely complete or unique.

Since glycogen and poly- $\beta$-hydroxybutyrate can be accumulated and degraded, what determines their amount in a cell? Is it simply a measure of the steady-state level of the monomer donor or is there some degree of control over the rate of synthesis or breakdown? We do not know the pathway of glycogen metabolism in Escherichia coli but in Agrobacterium tumefaciens there is a glycogen cycle similar to that in animal tissues (Madsen, 1961 a); it is shown in Fig. 3. Control seems to be exerted by the intracellular concentration of uridine diphosphate glucose which, if high, acts as a substrate for glycogen synthetase and inhibits glycogen phosphorylase (Madsen, 1961 $b$ ). Poly- $\beta$-hydroxybutyrate metabolism in bacteria has been studied by Merrick \& Doudoroff (1961), the pathways for synthesis and breakdown being summarized in Fig. 4. 
In order to demonstrate a storage function for a compound, it is necessary to show that the products of breakdown can be used for some purpose that gives the cell an advantage in the struggle for existence over other organisms not so endowed. There is evidence that both glycogen and poly- $\beta$-hydroxybutyrate can provide intermediates for the synthesis of proteins (Holme \& Palmstierna, 1956a; Doudoroff \& Stanier, 1959). This may allow an increment of growth and division which may well be important, particularly if the supply of the carbon and energy source is sporadic. It may also allow a more rapid adaptation to a different environment by the production of inducible enzymes or permeases. Further, poly- $\beta$-hydroxybutyrate breakdown has been shown to provide energy and intermediates for the process of sporulation (Slepecky \& Law, 1961). The breakdown of a reserve may help to preserve viability by providing the so-called energy of maintenance, the necessity of which has been shown by Mallette (1963) and by Marr, Wilson \& Clark (1963). It is

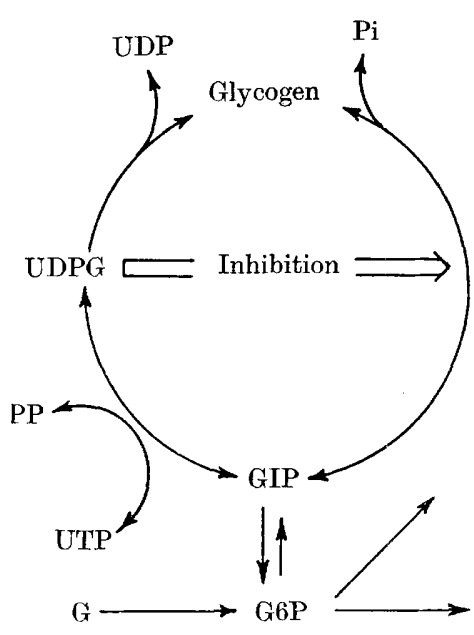

Fig. 3

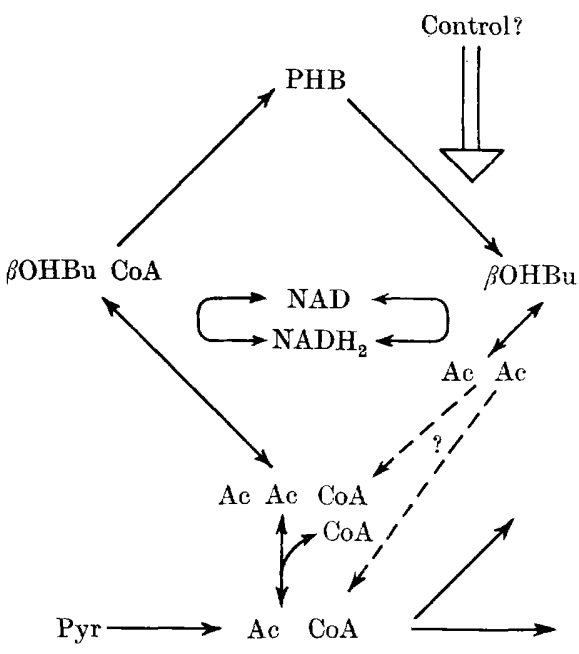

Fig. 4

Fig. 3. The glycogen cycle in Agrobacterium tumefaciens. $\mathbf{G}=$ glucose; $\mathbf{G 6 P}=$ glucose6-phosphate; G1P = glucose-1-phosphate; UTP = uridine triphosphate; UDP = uridine diphosphate; UDPG $=$ uridine diphosphate glucose; $\mathbf{P P}=$ inorganic pyrophosphate; Pi = inorganic orthophosphate. From Madsen $(1961 a, b)$.

Fig. 4. The metabolism of poly- $\beta$-hydroxybutyrate in Bacillus megaterium. $\mathbf{P y r}=$ pyruvate; $\mathbf{A c}=$ acetate $; \mathbf{A c} A \mathbf{c}=$ acetoacetate $\beta \mathrm{OHBu}=\beta$-hydroxybutyrate $; \mathbf{C o A}=$ coenzyme A; PHB = poly- $\beta$-hydroxybutyrate. From Merrick \& Doudoroff (1962) and Merrick, Doudoroff \& Wilkinson (unpublished results).

obvious, however, that the question of the preservation of viability is a complex one. Strange, Dark \& Ness (1961) have shown that death of Aerobacter aerogenes populations was preceded by degradation of protein, ribonucleic acid and polysaccharide and Postgate \& Hunter (1962) have analysed in great detail one of the factors involved in the survival of starved bacteria. It is evident that polymers such as protein and nucleic acid can be metabolized to provide carbon and energy without loss of viability. Indeed, Campbell, Gronlund \& Duncan (1963) have suggested that Pseudomonas aeruginosa synthesizes no specialized reserves. On the other hand, loss 
of viability of Micrococcus halodenitrificans can follow closely the loss of stored poly- $\beta$-hydroxybutyrate (Sierra \& Gibbons, 1962).

In conclusion, we can assume that a cell will tend to store any polymers that can be accumulated without decreasing the rate of growth. The nature of these polymers will depend primarily upon the rate-limiting step in growth and, therefore, upon the nature and level of nutrients in the medium. Probably the rate-limiting factor will either be in the synthesis of proteins and nucleic acids when reserves containing carbon, hydrogen and oxygen only will accumulate, or it will be in the primary degradative pathway of the carbon and energy source when no specialized carbon and energy reserves will accumulate.

\section{REFERENCES}

Barry, C., Gavard, R., Milhaud, G. \& Aubert, J. P. (1953). Étude du glycogène extrait de Bacillus megatherium. Ann. inst. Pasteur, 34, 605.

Campbell, J. J. R., Gronlund, A. F. \& Duncan, M. G. (1963). Endogenous metabolism of pseudomonas. Ann. N.Y. Acad. Sci. (in the Press).

Dagley, S. \& Johnson, A. R. (1953). The relation between lipid and polysaccharide contents of Bact. coli. Biochem. biophys. Acta, 11, 158.

Dawes, E. A. \& Ribbons, D. W. (1962). The endogenous metabolism of micro-organisms. Annu. Rev. Microbiol. 16, 241.

Doudoroff, M. \& Stanier, R. Y. (1959). Role of poly- $\beta$-hydroxybutyrate in the assimilation of organic carbon by bacteria. Nature, Lond. 183, 1440.

Foster, J. W. (1947). Some introspections of mold metabolism. Bact. Rev. 11, 166.

Holme, T. (1957). Continuous culture studies on glycogen synthesis in Escherichia coli B. Acta chem. scand. 11, 762.

Holme, T. \& Palmstierna, H. (1956 $a$ ). On the synthesis and breakdown of a glycogenlike polysaccharide in Escherichia coli B. Acta chem. scand. 10, 155.

Holme, T. \& Palmstierna, H. (1956b). Changes in glycogen and nitrogen-containing compounds in Escherichia coli B during growth in different media. 1. Nitrogen and carbon starvation. Acta chem. scand. 10, 578.

Macrae, R. M. \& Wilkinson, J. F. (1958a). The influence of cultural conditions on poly$\beta$-hydroxybutyrate synthesis in Bacillus megaterium. Proc. R. phys. Soc. Edinb. $27,73$.

Macrae, R. M. \& Wilkinson, J. F. (1958b). Poly- $\beta$-hydroxybutyrate metabolism in washed suspensions of Bacillus cereus and Bacillus megaterium. J. gen. Microbiol. 19, 210.

MaDSEn, N. B. $(1961 a)$. The occurrence and enzymic synthesis of glycogen in extracts of Agrobacterium tumefaciens. Biochim. biophys. Acta, 50, 194.

Madsen, N. B. (1961 b). The inhibition of glycogen phosphorylase by uridine diphosphate glucose. Biochem. Biophys. Res. Comm. 6, 310.

Mallette, M. F. (1963). Validity of the concept of energy of maintenance. Ann. N.Y. Acad. Sci. (in the Press).

Mandelstam, J. (1960). The intracellular turnover of protein and nucleic acids and its role in biochemical differentiation. Bact. Rev. 24, 289.

Marr, A. G., Wilson, E. H. \& Clark, D. J. (1963). The maintenance requirement of Escherichia coli. Ann. N.Y. Acad. Sci. (in the Press).

Merrick, J. M. \& DoudorofF, M. (1961). Enzymatic synthesis of poly- $\beta$-hydroxybutyric acid in bacteria. Nature, Lond. $189,890$.

Postgate, J. R. \& Hunter, J. R. (1962). 'The survival of starved bacteria. J. gen. Microbiol. 29, 233.

Ribbons, D. W. \& Dawes, E. A. (1963). Environmental and growth conditions affecting the endogenous metabolism of bacteria. Ann. N.Y. Acad. Sci. (in the Press).

Sierra, G. \& Grbbons, N. E. (1962). Role and oxidation pathway of poly- $\beta$-hydroxybutyric acid in Micrococcus halodenitrificans. Canad. J. Microbiol. 8, 255. 
Slepecky, R. A. \& LAw, J. H. (1961). Synthesis and degradation of poly- $\beta$-hydroxybutyric acid in connection with sporulation of Bacillus megaterium. J. Bact. 82, 37.

Stanier, R. Y., Doudoroff, M., Kunisawa, R. \& Contopoulou, R. (1959), The role of organic substrates in bacterial photosynthesis. Proc. nat. Acad. Sci., Wash. 45, 1246.

Strange, R. E., Dark, F. A. \& Ness, A. G. (1961). The survival of stationary phase cells of Aerobacter aerogenes stored in aqueous suspension. J. gen. Microbiol. 25, 61.

WiLkinson, J. F. (1959). The problem of energy-storage compounds in bacteria. Exp. Cell Res. (Suppl. 7), 111. 